\author{
Alena PAVELKOVÁ ${ }^{1 *}$, Vojtěch STEJSKAL ${ }^{1,2}$, Ondřejka VOLOŠČUKOVÁ ${ }^{1}$ \\ and Jaroslav NOSEK ${ }^{1}$
}

\title{
COST-EFFECTIVE REMEDIATION USING MICROSCALE ZVI: COMPARISON OF COMMERCIALLY AVAILABLE PRODUCTS
}

\begin{abstract}
Zero-valent iron is very effective in the treatment of groundwater contaminated with chlorinated hydrocarbons and solvents broadly used in industrial production. In terms of its sustainability and cost, a legitimate effort has been devoted to the optimization of the remediation process, which can be demanding and expensive. In this study, the application potential and fundamental properties of several commercial micro-sized zero-valent iron $(\mu \mathrm{ZVI})$ were investigated. Although the manufacturers report the basic parameters of $\mu \mathrm{ZVI}$, it has been shown that the actual reactivity of apparently similar products varies notably. This work was focused on monitoring of frequently occurring contaminants. The actual contaminated water from the Pisecna locality former landfill of industrial waste, with high levels of chlorinated ethenes and ethanes (PCE, TCE, cis-1,2-DCE and 1,2-DCA) was used for the experiment. The degree of dechlorination reached over $85 \% 32$ days after the application of $\mu \mathrm{ZVI}$ in several samples and a far higher reaction rate for smaller particles was observed. Also, the amount of cis-1,2-DCE, which is characterized by slow decomposition, decreased by more than $95 \%$ over the course of the experiment. Smaller particles showed a much longer sedimentation rate and gradual fractionation was also observed. Monitoring of ORP and $\mathrm{pH}$ also suggested that the smaller particles possessed a reduction capacity that was sufficiently high even at the end of the experiment. Laboratory tests with apparently similar $\mu Z V I$ samples indicated considerable differences in their reaction rate and efficiency.
\end{abstract}

Keywords: micro-sized zero-valent iron, chlorinated hydrocarbons degradation, commercial ZVI, cost-effective remediation

\section{Introduction}

The application of zero-valent iron (ZVI) is an innovative method for the remediation of contaminated groundwater and the demonstrable efficacy of contaminated site clean-up has gradually made the use of ZVI a well-established remedial technique [1-8]. In terms of general environmental sustainability, the importance of lifecycle costs is substantial for companies remediating contaminated sites and particular attention is paid to the optimal application conditions [9]. In this regard, there are several inherent aspects that need to be considered. Firstly, the fundamental physicochemical conditions of the contaminated site have to be properly specified, the type and spread of contamination; secondly, hydrogeological and geochemical parameters of the subsurface environment (hydraulic

\footnotetext{
${ }^{1}$ Institute for Nanomaterials, Advanced Technologies and Innovation, Technical University of Liberec, Studentská 2, 461 17, Liberec, Czech Republic, phone: +420485353 895, +420737618643, email: voloscukova.ondrejka@gmail.com; jaroslav.nosek1@tul.cz

${ }^{2}$ Photon Water Technology s.r.o., Hodkovická 109, 463 12, Liberec, Czech Republic, email: vojtech.stejskal@photonwater.com

* Corresponding author: alena.pavelkova@tul.cz
} 
conductivity, density, effective porosity, water composition, etc.) [10]. Based on the nature and extent of contamination, a suitable remedial technique or their combination eventually, needs to be selected. This includes the application method and the type of the remedial agent.

Chlorinated ethenes (CEs) are among the most frequently encountered classes of contaminants detected in groundwaters which are often sources of drinking water. The concentration of CEs at contaminated sites can vary due to many factors, including natural attenuation, volatilization, sorption or diffusion, which can dilute the concentration but not degrade or transform the contaminants. Decomposition takes place by abiotic and biotic transformations through oxidation and reduction reactions. Biotic degradation is mediated by naturally occurring microorganisms or injected commercial microbial cultures, which use the transfer of electrons in metabolic processes. Various bacterial strains arise depending on the conditions (anaerobic, anoxic, aerobic). Nevertheless, due to the complexity of the environmental processes, the degradation effects of bacterial strains and abiotic factors can overlap. Microbial decomposition depends on physical parameters such as temperature. Research conducted by Wing determined that a reduction of TCA (1,1,1-trichloroethane) can take place two times faster when the temperature is about $5{ }^{\circ} \mathrm{C}$ higher (in the range of $10-25{ }^{\circ} \mathrm{C}$ ) [3]. Furthermore, the degree of chlorination of contaminant is an important factor that should be considered. Several research projects were devoted to investigating the mechanisms of CE reduction $[11,12]$. Under the abiotic conditions the dechlorination pathway proceeds sequentially from PCE, TCE, cis-1,2-DCE and $\mathrm{VC}$ with the end products being ethene or ethane and the prevailing mechanism being reductive dechlorination. The degradation susceptibility of CEs, however, generally decreases with a less chlorinated molecule [13]. Incomplete dechlorination of PCE and TCE results in cis-1,2-DCE and VC, which often accumulate in the ground due to their low decomposition rate [14]. In reducing less chlorinated compounds (DCE, VC), various techniques are being developed. For example, induced degradation of DCE by microbes in the study [15] was performed by enrichment of the site with natural monoaromatic secondary plant metabolites. Lower concentrations of less chlorinated compounds can be effectively reduced microbially; nevertheless, highly concentrated contamination can be rather toxic for the microorganisms. An abiotic approach to enhance degradation processes is to create stronger reductive conditions with the application of zero-valent iron.

ZVI is highly effective in the reduction of many classes of chlorinated hydrocarbons (CHC) $[16,17]$. An important parameter related to reductive capacity and thus the ability of ZVI to degrade CHC is the size of the particles [18]. The size along with the topography are decisive for the surface specific area and, thus, the availability of $\mathrm{Fe}^{0}$ atoms to come into contact with CHC [19]. The higher the surface area, the higher reductive capacity can be expected; however, depending on the environment the capacity is also being consumed in further reductive reactions with water or dissolved ions. Considering the application purposes, a range of iron particle sizes can be used for remediation [20]. Millimetre-sized particles are used for example in permeable reactive barriers, where their long-term activity is demonstrated, although their efficiency is low. Furthermore, very large quantities of iron filings are typically required [21]. In recent research, great attention has been devoted to investigating the use of nano-sized ZVI for remedial purposes [4, 19, 22, 23]. The main advantage of nano-sized ZVI particles is their high reductive capacity and reactivity, due to their large specific surface area. Moreover, they can be used in less accessible areas or areas with low hydraulic conductivity, where due to their smaller size, an enhanced ability to 
migrate is expected [24]. However, nZVI is significantly more costly than other iron varieties, and currently can be up to $100 \mathrm{USD} / \mathrm{kg}$; besides that, there is essentially no track record regarding its long-term performance. On the other hand, far less attention and research has been focused on the investigation of real applications of micro-sized ZVI for remediation. Compared to nZVI, micro-sized ZVI reacts moderately and possess extended longevity, which may be a welcome compromise, especially for sites with higher porosity and hydraulic conductivity. Additionally, the microscale iron market is more robust as there are many well-established manufacturers of iron powders for a myriad of industrial functions including remediation, unlike nZVI. Automated processes and QA/QC ensure high capacity manufacture of the optimal product what also reflects the lower costs of $\mu \mathrm{ZVI}$ [25].

Manufacturers of commercial ZVI report general information about the size of microparticles, which can be comparable at first sight; however, the crucial properties affecting dechlorination efficiency are not fully appreciated. For example, major factors regarding the propensity of ZVI to agglomerate and their morphology, which affect the actual effective surface of particles can significantly influence their reactivity [26]. In addition, the mobility of the particles in the ground leads to a specific sedimentation rate of the material in the rock environment and clogging of injection technology and can also contribute to the final dechlorination effect [27].

The aim of this research is to examine commercially produced $\mu \mathrm{ZVI}$, and to characterize the efficiency and application potential with regards to the parameters reported by manufacturers. Five comparable microscale zero-valent iron materials from various producers were investigated. The manufacturers reported a particle size up to D80 $=63 \mu \mathrm{m}$, high zero-valent iron content and a minimum presence of impurities. The cost of each iron assessed was less than $3 \mathrm{USD} / \mathrm{kg}$. Information provided by this research may be valuable for users to effectively optimize their remedial processes from setting of technological parameters to budgeting.

\section{Materials and methods}

\section{Types of studied $\mu \mathrm{ZVIs}$}

Five commercially available microscale zero-valent iron particle materials with comparable characteristics were evaluated. All available information provided by manufacturers are summarized in Table 1.

Summary information of the samples

\begin{tabular}{|c|c|c|c|c|c|}
\hline Sample & Company & Country & $\begin{array}{c}\text { Product } \\
\text { name }\end{array}$ & $\begin{array}{c}\text { Grain size } \\
{[\mu \mathrm{m}]}\end{array}$ & $\begin{array}{c}\text { Iron content } \\
{[\%]}\end{array}$ \\
\hline$\mu Z V I \_1$ & $\begin{array}{l}\text { Pometon } \\
\text { powders }\end{array}$ & Italy & Ferchim & $80 \%<63$ & 98 \\
\hline$\mu Z V I \_2$ & Hepure & USA & Ferox PRB & $96 \%<60$ & 95 \\
\hline$\mu Z V I \_3$ & Rio Tinto & Canada & Atomet & $90 \%<45$ & 98 \\
\hline$\mu Z V I \_4$ & Höganäs & Sweden & MH300 & $80 \%<45$ & 98.5 \\
\hline $\mu$ ZVI_5 & LAC & $\begin{array}{c}\text { Czech } \\
\text { Rep. }\end{array}$ & LAC 2000 & $85 \%<50$ & 97 \\
\hline
\end{tabular}




\section{Laboratory reactor test}

The dechlorination efficiency was monitored in laboratory reactor tests. The tests were performed in a set of $20 \mathrm{~cm}^{3}$ hermetically-sealed vials equipped with Teflon septum (to avoid leakage of the contaminant), where the contaminated water and ZVI microparticles were dispensed. Control tests in vials without $\mu$ ZVI were conducted at the same time. The groundwater used in this research was taken from a contaminated site called Pisecna (see the description below). Before the tests, the chemical composition of the water was determined. In addition to the determination of ions (ammonium ions $<0.25 \mathrm{mg} / \mathrm{dm}^{3}$, COD-Cr $25 \mathrm{mg} / \mathrm{dm}^{3}$, nitrates $3.11 \mathrm{mg} / \mathrm{dm}^{3}$, nitrites $0.25 \mathrm{mg} / \mathrm{dm}^{3}$, sulphates $36.4 \mathrm{mg} / \mathrm{dm}^{3}$, sulphites $<1 \mathrm{mg} / \mathrm{dm}^{3}$, iron $0.062 \mathrm{mg} / \mathrm{dm}^{3}$ and manganese $0.017 \mathrm{mg} / \mathrm{dm}^{3}$ ), the water was analysed for the presence of CEs $\left(10,800 \mu \mathrm{g} / \mathrm{dm}^{3}\right.$ of PCE, 17,555 $\mu \mathrm{g} / \mathrm{dm}^{3}$ of TCE, $1,399 \mu \mathrm{g} / \mathrm{dm}^{3}$ of DCE and $7,550 \mu \mathrm{g} / \mathrm{dm}^{3}$ of $\left.1,2-\mathrm{DCA}\right)$. Groundwater $\left(15 \mathrm{~cm}^{3}\right)$ was poured into vials and $0.075 \mathrm{~g}$ of $\mu \mathrm{ZVI}$ (concentration of $5 \mathrm{~g} / \mathrm{dm}^{3}$ ) was added. The vials were then placed into a vertical shaker (PluNoTech s.r.o. Czech Republic) and the mixture was mixed continuously with two-minute breaks between each movement. Sampling (monitoring of physicochemical properties) was performed after 3, 7, 15 and 32 days and all of the measurements were performed in triplicate.

\section{Decription of the contaminated site Pisecna}

The Pisecna site was a lined landfill since 1970s, where an industrial waste containing CEs was deposited. In 1996-97 the landfill was excavated, and the area was recultivated. Currently, the area is monitored for the occurrence of secondary contamination and there were made application wells for further remediation, because the levels of chlorinated hydrocarbons are still too high. As a result of landfilling, the rock environment was contaminated with a mixture of CEs in which $95 \%$ of chlorinated ethenes (ClE) predominate, the remainder being chlorinated ethanes (ClA). Sum of ClE consisted of $52 \%$ PCE, $46 \%$ TCE and about $2 \%$ of 1,2-cis-DCE. More than $98 \%$ of ClA is was present in the form of 1,2-DCA. The rock environment can be characterized as highly geologically complex, with fracture-stream flow and medium collector transmissivity in the interval of $10^{-4}-10^{-3} \mathrm{~m}^{2} / \mathrm{s}$. The collector base is $25-35 \mathrm{~m}$ below the terrain, the groundwater level at the site is in the range of $10-20 \mathrm{~m}$ below the terrain. The source of CEs contamination is located in 6-10 $\mathrm{m}$ below the terrain.

\section{Laboratory analyses, measurements and calculations}

Physical-chemical characteristics - oxidation reduction potential (ORP) and $\mathrm{pH}$ were measured using a WTW 3430 Multimeter (WTW, Germany); ORP was measured by an $\mathrm{Ag} / \mathrm{Cl}$ electrode and recalculated against a standard hydrogen electrode. Determination of CEs was performed according to EPA method $8260 \mathrm{~B}$ by GC/MS (Thermo Trace 1310) (Thermo SQTM $8000 \mathrm{EVO}$ ) and the concentration of reductive dehalogenation products (methane, ethane, ethene) was measured by GC/FID (Varian Saturn 3800). The rate of decrease of CEs was evaluated according to the pseudo-first order kinetic model.

The degree of dechlorination $D$ was calculated according to equation (1) using molar concentrations:

$$
D=\frac{[\mathrm{TCE}]+2 \cdot[\mathrm{DCE}]+3 \cdot[\mathrm{VC}]+4 \cdot[\text { ethene }]+4 \cdot[\text { ethane }]}{4 \cdot([\mathrm{PCE}]+[\mathrm{TCE}]+[\mathrm{DCE}]+[\mathrm{VC}]+[\text { ethene }]+[\text { ethane }])} \cdot 100[\%]
$$


The degree of dechlorination is a value in the range from $0-100 \%$, when the value $100 \%$ refers to the complete dechlorination of CEs to the non-chlorinated products ethene and ethane [28].

\section{Sedimentation test}

Sedimentation of iron particles was examined using a specially assembled device, constructed also for online monitoring. The device consisted of four components: laboratory scales, a measuring cylinder, a support and a PC output. For the experiments, a graduated cylinder with a volume of $2 \mathrm{dm}^{3}$ was filled with tap water (distilled water was not appropriate due to very low ionic strength), after that $10 \mathrm{~cm}^{3}$ of suspension of ZVI $\left(3 \mathrm{~g} / 10 \mathrm{~cm}^{3}\right)$ (ZVI was used without any further modification) was pipetted into the centre of the water in the cylinder to disperse the iron particles in the water as much as possible and at the same time to prevent the iron particles from clinging to the walls and hinges. The time and the increase in weight were then monitored.
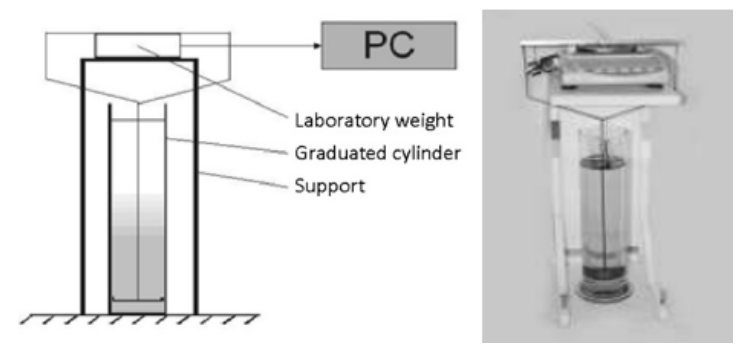

Fig. 1. Device assembled for sedimentation tests

\section{Microbiology assessment}

The effect of microbial activity was evaluated in two separate reactors with a volume of $2.5 \mathrm{dm}^{3}$; one of which was provided with $\mu \mathrm{ZVI}\left(5 \mathrm{~g} / \mathrm{dm}^{3}\right)$. Groundwater from the same location was taken at a different time; hence, the initial concentration of CEs differed. After the test has finished, $0.5 \mathrm{dm}^{3}$ of water from each reactor was filtered through a $0.22 \mu \mathrm{m}$ pore membrane. DNA was isolated from the filters with the collected microorganisms by the Fast DNA SPINKit for Soil (MP Biomedicals, GmbH Germany) according to the manufacturer's protocol. The extracted DNA was used as a template for real-time PCR amplification. Specific genes were used for detection of ongoing reductive dehalogenation (Dre, DHC-RT and Dsb).

\section{Electron microscopy}

SEM Carl Zeiss ULTRA Plus (Carl Zeiss AG, Germany) with an EDS Oxford X-Mas 20 (Oxford Instruments, UK) was used for characterization of the morphology, size and agglomeration of particles. The SEM Carl Zeiss ULTRA Plus was operated by Smart SEM software and EDS Oxford X-Mas 20 by Aztec software. Additionally, the specific surface area of the scaffolds was measured via $\mathrm{N}$ adsorption and calculated from BET equation. 


\section{Results and discussion}

\section{Chemistry - CE degradation, ORP and pH}

The effect of the $\mu \mathrm{ZVI}$ was monitored by measuring the ORP and $\mathrm{pH}$. The freshly taken sample of the contaminated water had the value of ORP $278 \mathrm{mV}$ and $\mathrm{pH}$ was 6.9 . Figure 2 shows the development of the ORP and $\mathrm{pH}$ throughout the experiment. The reductive effect of the added $\mu \mathrm{ZVI}$ is characterized by a sharp decrease in the ORP. The value of $-600 \mathrm{mV}$ was observed for all of the examined samples of $\mu \mathrm{ZVI}$ within three days, except in the case of the control reactors. Such a low value of ORP may indicate that the concentration of $\mu \mathrm{ZVI}$ used in the batch tests was fairly high, as was also reported in study [29] when a low ORP was reached in a highly concentrated system. Due to this, the ORP stayed low compared to the control and also for a longer period of time compared to the previously published data, where nZVI at a low concentration was used and the ORP began to increase after five days [30]. A decrease in the ORP is accompanied with an increase in the $\mathrm{pH}$ up to a value of 10.2, which is due to the reduction of water (e.g. formation of hydroxide and hydrogen). From the $\mathrm{pH}$ data, it can be seen that in the reactors with ZVI_3 and ZVI_5 the pH is higher, which may indicate a higher reductive capacity of these samples, because an elevated water reduction occurred. On the contrary, the $\mathrm{pH}$ in the control reactor remained constant until the end of the experiment, except the deviation from the initial value which occurred due to natural character of a sample (non-sterile water) and sample manipulation under the atmospheric conditions.

a)

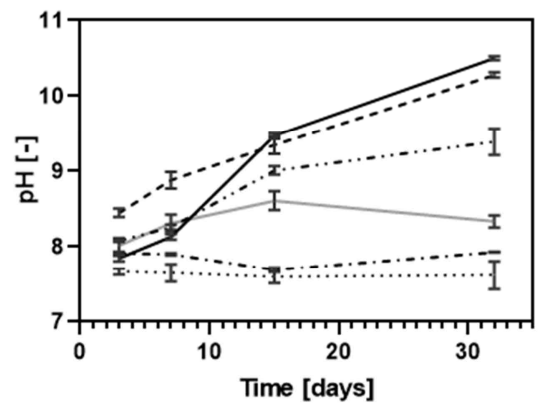

b)

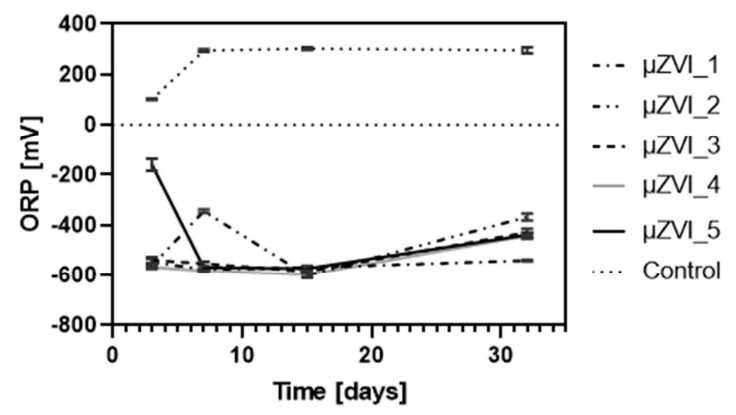

Fig. 2. Development of: a) $\mathrm{pH}$ and b) ORP during the reactor test

\section{Reactivity of $\mu \mathrm{ZVI}$}

The course of dechlorination in the reactors with applied $\mu \mathrm{ZVI}$ compared to the control reactor without $\mu \mathrm{ZVI}$ is depicted in Figure 3. A decrease in the contaminants is apparent in all of the reactors. The drop of the PCE and TCE was more pronounced compare to the dechlorination of cis-1,2-DCE what took place at a slower rate. The decrease of the level of chlorinated compounds from the initial value to the value of first sampling occurred likely due to combination of several factors what was exposure to atmospheric conditions, manipulation with the samples, microbial activity and the beginning activity of $\mu \mathrm{ZVI}$. Nevertheless, after the sealing of the samples in hermetically closed vials, any leakage or exposition to atmospheric conditions was avoided. After the first sampling in third day of the experiment the prevailing effect of $\mu \mathrm{ZVI}$ can be observed, based also on the low ORP. 
Recent research demonstrated that 1,2-DCA does not react with ZVI [11]. Nevertheless 1,2-DCA is efficiently degradable by microorganisms [31]. As can be seen in Figure 3, the concentration of 1,2-DCA decreased moderately at the start of the experiment or remained rather constant in the reactors with the applied $\mu \mathrm{ZVI}$. On the contrary, complete decomposition was observed in the control reactor, which may be attributed to the microbial activity.

a)

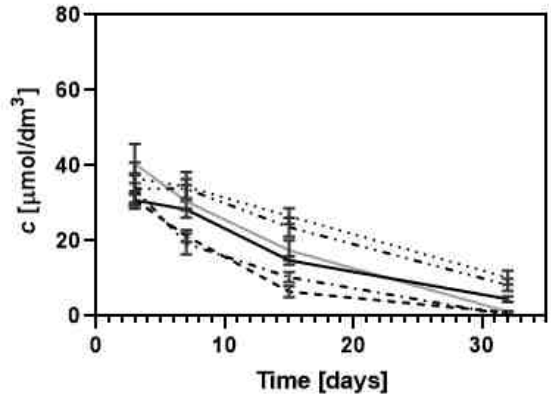

c)

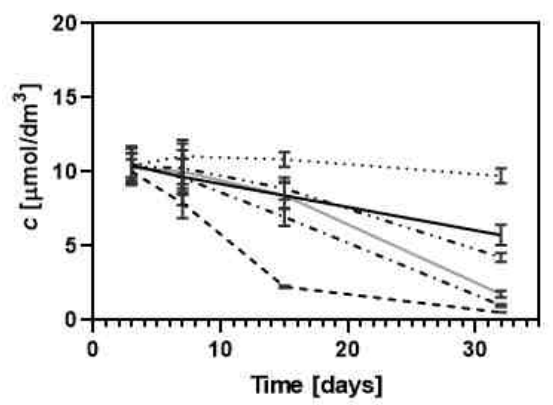

b)

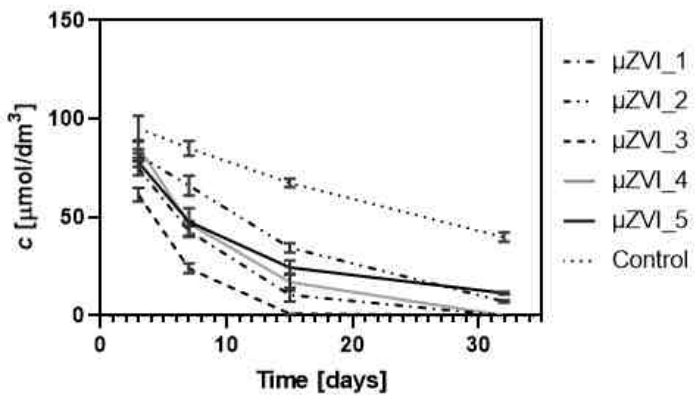

d)

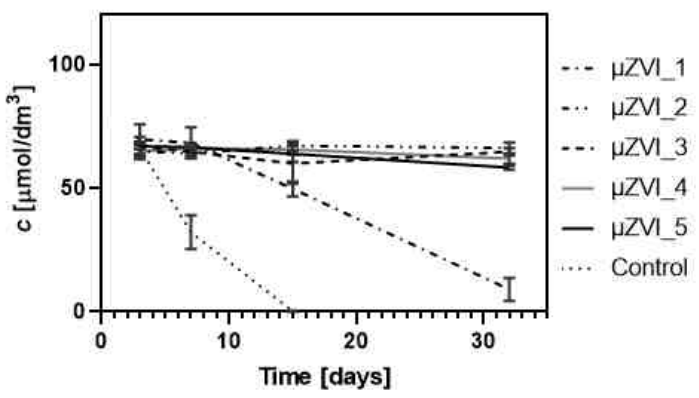

Fig. 3. Molar concentration of CEs, the progress during the reactor test (with initial concentration): a) PCE $\left(65 \mu \mathrm{mol} / \mathrm{dm}^{3}\right)$, b) TCE $\left(133 \mu \mathrm{mol} / \mathrm{dm}^{3}\right)$, c) cis-1,2-DCE $\left(14 \mu \mathrm{mol} / \mathrm{dm}^{3}\right)$, d) 1,2-DCA $\left(76 \mu \mathrm{mol} / \mathrm{dm}^{3}\right)$

Based on this observation, an assessment of the halorespiring bacterium strains (Dehalococcoides, Dehalobacter, Desulfitobacterium) in the control reactor was performed and the presence of Desulfitobacterium was confirmed. According to previously published research [32], Desulfitobacterium strains are capable of dechlorinating PCE and TCE into cis-DCE, and 1,2-DCA into ethane under certain conditions, to some extent based on the initial concentrations. Research published elsewhere [33] even reported a synergistic tendency of the Desulfitobacterium sp. strain Y-51 and ZVI used for the dechlorination at the same time; however, this effect was not proved likely due to high a $\mu \mathrm{ZVI}$ content and strong reductive conditions which can be incompatible with the bacterial strain occurrence [34]. Conversely, the toxic effect on the groundwater microbial community was confirmed in a comparative experiment (Fig. 4) when no halorespiring bacterium strains were detected in the reactor with applied $\mu \mathrm{ZVI}$. A toxic effect of ZVI on the groundwater microbial 
community was also proven in a study by Kara M. Zabetakis [35], which also considered the impact of the particle size.

To clarify the abiotic and biotic effects on the decomposition of CEs, a comparison of the changes in concentrations of CEs in the reactor with the applied model $\mu$ ZVI (abiotic factor) and the control reactor without $\mu \mathrm{ZVI}$ (with naturally-occurring microbial strains) was performed (Fig. 4). To compare only the effect of $\mu \mathrm{ZVI}$ and microorganisms an independent experiment was performed; the concentration of contaminants differed due to different time of sample withdrawn, however present contaminants were the same. In the reactor with the applied $\mu \mathrm{ZVI}$, complete degradation of TCE and PCE was observed within 43 days. The decrease in cis-1,2-DCE is less apparent from the graph; however, no cis-1,2-DCE was detected after day 34. On the contrary, the concertation of DCA slightly increased during the experiment due to a reduction in the more chlorinated compounds. In comparison, the 1,2-DCA in control reactor degraded completely, but the concentrations of PCE and TCE were still high (approximately $8,000 \mu \mathrm{g} / \mathrm{dm}^{3}$ of TCE, and 2,500 $\mu \mathrm{g} / \mathrm{dm}^{3}$ of PCE). The concentration of cis-1,2-DCE was negligible. Therefore, it can be assumed that the initial decrease in the reactors (Fig. 3) is a result of the microbial activity until the strong reductive conditions occur due to the $\mu \mathrm{ZVI}$.

a)

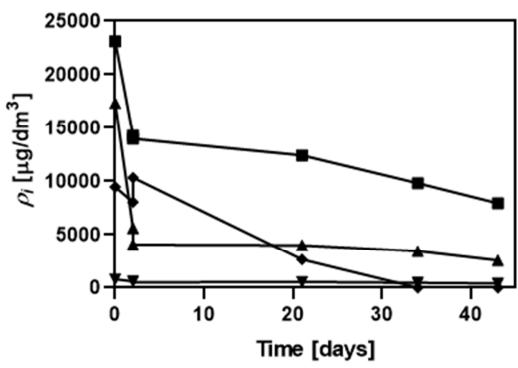

b)

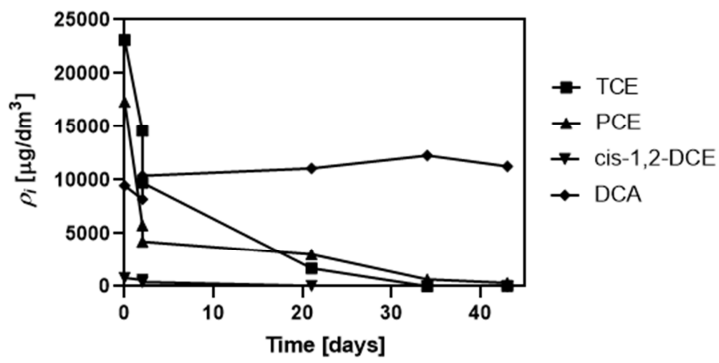

Fig. 4. Mass concentration of CEs; the comparison of the course during the experiment: a) control reactor, b) reactor with applied $\mu \mathrm{ZVI}$; effect of microbial activity

The tendency of contaminants to dehalogenate can be seen from the data. PCE degraded more readily compared to TCE; however, the rate was rather slow. This is in agreement with the theory that the efficiency of the dechlorination is based on the degree of substance chlorination [36]. On the contrary to PCE and TCE, which easily undergo reductive dechlorination, conversion of cis-1,2-DCE was limited. Therefore, it often accumulates in aquifers, as reported elsewhere [37]. The most significant difference in the reactivity of $\mu \mathrm{ZVI}$ was observed in the reduction of cis-1,2-DCE. Promising results were provided by $\mu \mathrm{ZVI} 3$, which reduced more than $95 \%$ of cis-1,2-DCE at the end of experiment and showed the highest reaction rates of all the $\mu \mathrm{ZVI}$ samples and reduction of all of the examined contaminants (see Table 2). The long-lasting reactivity of $\mu Z V I \_3$ can be also derived from the ORP, which remained around $-600 \mathrm{mV}$ even at the end of experiment in contrast to the other $\mu \mathrm{ZVI}$ samples. The level of the decomposition of CEs by $\mu \mathrm{ZVI} 3$ is also in good agreement with the evolution of gaseous products of reduction (Fig. 5), when the higher efficiency of CE conversion resulted in elevated concentrations of ethene and ethane. 
Pseudo-first order degradation rate constants for the dechlorination of CEs

\begin{tabular}{|c|c|c|c|c|c|c|}
\hline & \multicolumn{2}{|c|}{ PCE } & \multicolumn{2}{|c|}{ TCE } & \multicolumn{2}{|c|}{ cis-1,2-DCE } \\
\hline & $k\left[\right.$ day $\left.^{-1}\right]$ & $R^{2}[-]$ & $k\left[\mathrm{day}^{-1}\right]$ & $R^{2}[-]$ & $k\left[\mathrm{day}^{-1}\right]$ & $R^{2}[-]$ \\
\hline$\mu Z V I \_1$ & 0.20 & 0.986 & 0.17 & 0.998 & 0.03 & 0.970 \\
\hline$\mu Z V I 22$ & 0.15 & 0.893 & 0.11 & 0.976 & 0.03 & 0.909 \\
\hline$\mu Z V I 3$ & 0.21 & 0.982 & 0.25 & 0.999 & 0.11 & 0.997 \\
\hline$\mu Z V I$ _4 & 0.12 & 0.954 & 0.15 & 0.999 & 0.01 & 0.934 \\
\hline$\mu Z V I \_5$ & 0.19 & 0.937 & 0.19 & 0.996 & 0.11 & 0.933 \\
\hline control & 0.13 & 0.922 & 0.10 & 0.957 & - & 0.922 \\
\hline
\end{tabular}

Assuming the reductive dechlorination is the main pathway in degradation of contaminants, an evolution of the ethene and ethane was observed (Fig. 5). Provided that the remediated system is not isolated the decrease of a chlorinated compound does not have to be a direct evidence of the proceeding reductive dechlorination, whereas the evolution of non-chlorinated products proves the dechlorination. Results suggest that $\mu \mathrm{ZVI} 3$ 3 provides the decomposition of CEs directly to ethene and ethane, with generation minimum cis-1,2-DCE or its gradual reduction. Similar trend of the evolution of products, but lower levels showed sample $\mu$ ZVI_5 even though the reported size of $\mu$ ZVI_5 was higher and thus the lower available surface area would be expected.

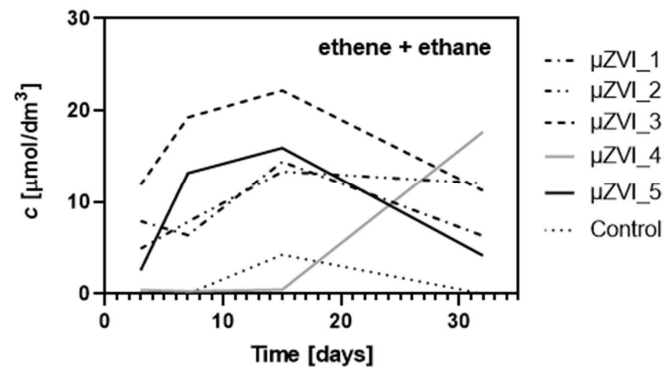

Fig. 5. The sum of the molar concentration of ethene and ethane - products of the CEs degradation, the evolution during the experiment

The specific surface area of iron particles

\begin{tabular}{|c|c|c|}
\hline Sample & $\begin{array}{c}\text { Specific surface } \\
\text { area }\left[\mathbf{m}^{2} \cdot \mathbf{g}^{-1}\right]\end{array}$ & $\begin{array}{c}\text { Correlation } \\
\text { coefficient } \boldsymbol{R}^{2}[-]\end{array}$ \\
\hline$\mu Z V I \_1$ & 0.05 & 0.9999 \\
\hline$\mu Z V I \_2$ & 0.10 & 0.9999 \\
\hline HZVI_3 & 0.30 & 0.9999 \\
\hline $\mu$ ZVI_4 & 0.05 & 0.9999 \\
\hline MZVI_5 & 0.12 & 0.9999 \\
\hline
\end{tabular}

The SEM analysis (Fig. 8) however showed more ragged surface structure of the $\mu Z V I$ 5 sample. This observation was afterwards proved by the measurement of the specific surface area what revealed the second highest value after $\mu$ ZVI_3 (Table 3). Other tested $\mu \mathrm{ZVs}$, showed a lower evolution of ethene and ethane, what could be related to the 
smaller specific surface area, and higher amount of intermediate product cis-1,2-DCE. In the control reactor, it can also be seen the generation of products of dehalogenation what indicates the bacterial activity.

To objectively evaluate the course and efficiency of decontamination, the results were expressed as a degree of dechlorination, a parameter which comprises the molar concentrations of PCE, TCE, DCE, VC, ethene and ethane (Fig. 6). At the end of the experiment, $\mu \mathrm{ZVI} \_3, \mu \mathrm{ZVI}$ 1 1 and $\mu \mathrm{ZVI} \_4$ showed an overall degree of dechlorination of approximately $85 \%$; however, $\mu \mathrm{ZVI} 3$ was more efficient in terms of the rate of dechlorination. Fifteen days after the application of $\mu \mathrm{ZVI} 3$, the reduction of contaminants reached $75 \%$, while the other samples exhibited much lower efficiency, with the maximum being approximately $45 \%$. The enhanced reactivity of $\mu$ ZVI_3 compared to the other samples may be related to the higher number of smaller particles, which possess a higher specific surface area [38].

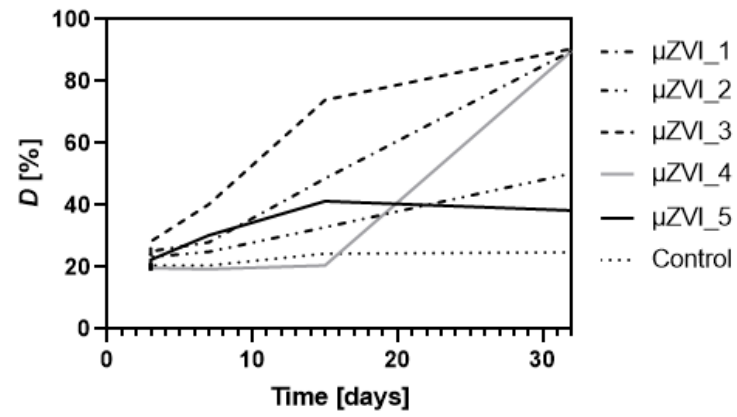

Fig. 6. The course of the degree of dechlorination during the experiment

\section{Sedimentation rates}

Sedimentation tests provide basic information regarding the essential particle properties referring to remediation ability. The sedimentation rate directly corresponds to the size of particles, while the shape of the sedimentation curve further suggests the fractionating of the particles or the formation of agglomerates. The rates of sedimentation are depicted in Figure 7. The sedimentation curves of the particular materials are normalized by the total weight of the applied iron so that they can be compared to each other on the same scale.

Providing all the particles possess very similar densities it can be assumed the greater the particle size, the higher the sedimentation rate. This is directly related to their decreased ability to migrate, when the suspension is applied into the ground [39]. The commercial $\mu$ ZVI samples used in this research showed rather heterogeneous and non-spherical character; therefore, the sedimentation rate does not necessarily reflect the size of particles reported from the manufacturers, but refers to the shape, specific density, surface morphology and further related factors [40]. The fastest sedimentation rate was shown by $\mu Z V I \_1$ all of the particles had settled down after nine seconds. Although the reported size of this sample was not the greatest, the higher sedimentation rate may be related to the elevated content of iron according to the manufacturer's data. Furthermore, the manufacturer reported a grain size of $80 \%<45 \mu \mathrm{m}$; hence, some fractionation could be 
expected, but the sedimentation curve denotes the presence of only one fraction. More interesting results were provided by $\mu \mathrm{ZVI} \_1$ and $\mu \mathrm{ZVI} \_3 . \mu \mathrm{ZVI} \_1$ completely settled down after 87 seconds, while sedimentation of $\mu \mathrm{ZVI} 33$ took place after 472 seconds, which may indicate improved subsurface transport ability in remediation process.

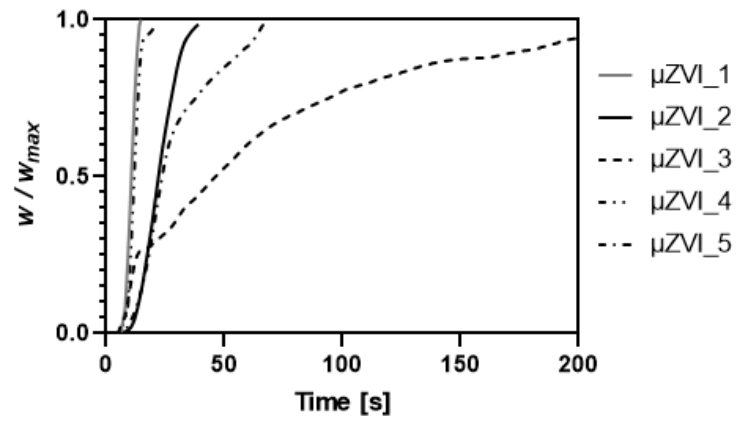

Fig. 7. The weight ratio of the particles in time; sedimentation rates of particular $\mu$ ZVI materials

Figure 8 shows the SEM images of samples of $\mu$ ZVIs. All of the samples exhibited a non-spherical, irregular shape with no evidence of aggregation. A substantial diversity in the size and morphology can be seen; however, it was proven that the particles of $\mu \mathrm{ZVI} 3$ possessed the smallest size of approximately $30 \mu \mathrm{m}$, which is in good agreement with the demonstrated increased reactivity of this sample.

a)

HZVI 1

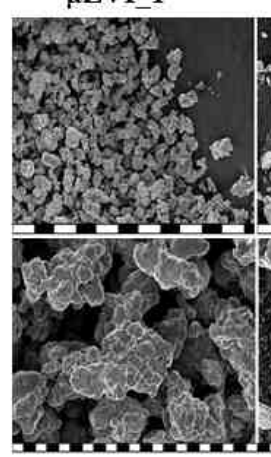

HZVI 2

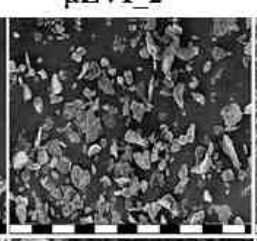

HZVI 3

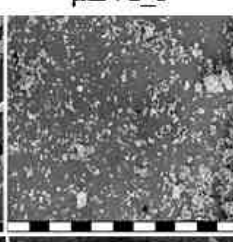

HZVI 4

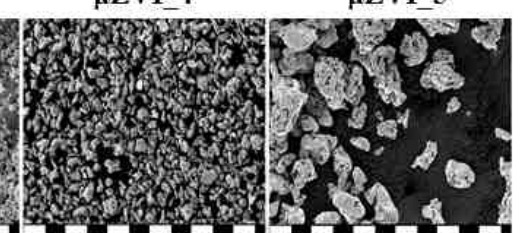

Fig. 8. SEM of the tested $\mu$ ZVI samples. Scale: a) $100 \mu \mathrm{m}$; b) $10 \mu \mathrm{m}$

\section{Conclusion}

This research was conducted primarily to support technological groups dealing with the remediation of contaminated groundwater. The reactivity with chlorinated hydrocarbons and basic properties crucial for the real application were investigated. Provided that the micro sized ZVI is being used more often and in large scale applications the attention was focused on the practical aspects of this material. Five commercially available microscale zero-valent iron particles with comparable properties reported by the manufacturer were 
examined. All of the samples were selected considering their cost, which did not exceed $3 \mathrm{USD} / \mathrm{kg}$.

The systems were characterised based on a laboratory reactor test with real groundwater contaminated by CEs from the Pisecna site. The experiments showed a degree of dechlorination above $85 \%$. During the test, the effect of microbial activity on dechlorination was initially observed; however, this effect was lately diminished due to high reductive conditions induced by $\mu \mathrm{ZVI}$. The main differences in dechlorination were in velocity and efficiency. In this regard, the importance of the particle size was confirmed. Smaller particles showed a higher capacity to degrade CEs and the decontamination was accelerated compared to larger particles of $\mu \mathrm{ZVI}$. Moreover, the enhanced ability to reduce cis-1,2-DCE was demonstrated.

The sample with $\mu Z V I \_3$ had approximately half the particle size of than other studied $\mu Z$ VIs - approximately $30 \mu \mathrm{m}$. This property resulted in enhanced reactivity along with low sedimentation, which is beneficial the application to the ground by injection.

The real potential of $\mu \mathrm{ZVI}$ could be as an additional agent for remediation where nZVI is used, to prolong the longevity and increase the effectiveness of CE reduction. Undoubtedly, there is also the huge benefit in lowering the cost of remediation, while maintaining the high efficiency of the site decontamination. A further application benefit is the use of $\mu \mathrm{ZVI}$ as a low-cost material to support decontamination only in the presence of microorganisms. Microorganisms can successfully decompose CEs; however, the required duration is rather long and, more importantly, the detoxification process via microorganisms is limited.

\section{Acknowledgements}

The research presented in this article was supported by the Research Infrastructures NanoEnviCz (Project No. LM2015073) supported by the Ministry of Education, Youth and Sports of the Czech Republic and the project Pro-NanoEnviCz (Reg. No. CZ.02.1.01/0.0/0.0/16_013/0001821) supported by the Ministry of Education, Youth and Sports of the Czech Republic and the European Union - European Structural and Investments Funds in the frame of Operational Programme Research Development and Education.

\section{References}

[1] Matheson LJ, Tratnyek PG. Reductive dehalogenation of chlorinated methanes by iron metal. Environ Sci Technol. 1994;28(12):2045-53. DOI: 10.1021/es00061a012.

[2] Cantrell KJ, Kaplan DI, Wietsma TW. Zero-valent iron for the in situ remediation of selected metals in groundwater. J Hazard Mater. 1995;42(2):201-12. DOI: 10.1016/0304-3894(95)00016-N.

[3] Wing MR. Apparent first-order kinetics in the transformation of 1,1,1-trichloroethane in groundwater following a transient release. Chemosphere. 1997;34(4):771-81. DOI: 10.1016/S0045-6535(97)00004-0.

[4] Cook SM. Assessing the use and application of zero-valent iron nanoparticle technology for remediation at contaminated sites. 2009:39. Available from: https://clu-in.org/download/techdrct/cook_\%20zvi_aug2009.pdf.

[5] Xiong Z, Kaback D, Bennett PJ. A case study of using zero-valent iron nanoparticles for groundwater remediation. AGU Fall Meeting Abstracts. 2011:H53B-1426. Available from: https://ui.adsabs.harvard.edu/abs/2011AGUFM.H53B1426X/abstract.

[6] Mueller NC, Braun J, Bruns J, Černík M, Rissing P, Rickerby D, et al. Application of nanoscale zero valent iron (NZVI) for groundwater remediation in Europe. Environ Sci Pollut Res. 2012;19(2):550-8. DOI: 10.1007/s11356-011-0576-3. 
[7] Fu F, Dionysiou DD, Liu H. The use of zero-valent iron for groundwater remediation and wastewater treatment: A review. J Hazard Mater. 2014;267:194-205. DOI: 10.1016/j.jhazmat.2013.12.062.

[8] Phenrat T, Lowry GV, Babakhani P. Nanoscale zerovalent iron (NZVI) for environmental decontamination: A brief history of 20 years of research and field-scale application. In: Phenrat T, Lowry GV, editors. Nanoscale Zerovalent Iron Particles for Environmental Restoration: From Fundamental Science to Field Scale Engineering Applications. Cham: Springer International Publishing; 2019:1-43. DOI: 10.1007/978-3-319-95340-3_1.

[9] Chen X, Ji D, Wang X, Zang L. Review on nano zerovalent iron (nZVI): From modification to environmental applications. IOP Conf Series: Earth and Environ Sci. 2017;51:012004. DOI: 10.1088/1742-6596/51/1/012004.

[10] Macé C, Desrocher S, Gheorghiu F, Kane A, Pupeza M, Cernik M, et al. Nanotechnology and groundwater remediation: A step forward in technology understanding. Remediation. 2006;16(2):23-33. DOI: 10.1002/rem.20079.

[11] Tobiszewski M, Namieśnik J. Abiotic degradation of chlorinated ethanes and ethenes in water. Environ Sci Pollut Res Int. 2012;19(6):1994-2006. DOI: 10.1007/s11356-012-0764-9.

[12] Liu Y, Majetich SA, Tilton RD, Sholl DS, Lowry GV. TCE dechlorination rates, pathways, and efficiency of nanoscale iron particles with different properties. Environ Sci Technol. 2005;39(5):1338-45. DOI: 10.1021/es049195r

[13] Hunkeler D, Abe Y, Broholm MM, Jeannottat S, Westergaard C, Jacobsen CS, et al. Assessing chlorinated ethene degradation in a large scale contaminant plume by dual carbon-chlorine isotope analysis and quantitative PCR. J Contam Hydrol. 2011;119(1-4):69-79. DOI: 10.1016/j.jconhyd.2010.09.009.

[14] Lee W, Batchelor B. Abiotic reductive dechlorination of chlorinated ethylenes by soil. Chemosphere. 2004;55(5):705-13. DOI: 10.1016/j.chemosphere.2003.11.033.

[15] Fraraccio S, Strejcek M, Dolinova I, Macek T, Uhlik O. Secondary compound hypothesis revisited: Selected plant secondary metabolites promote bacterial degradation of cis-1,2-dichloroethylene (cDCE). Sci Rep. 2017;7(1):8406. DOI: 10.1038/s41598-017-07760-1.

[16] Waclawek S, Nosek J, Cádrová L, Antos V, Cerník M. Use of various zero valent irons for degradation of chlorinated ethenes and ethanes. Ecol Chem Eng S. 2015;22(4):577-87. DOI: 10.1038/s41598-017-07760-1.

[17] Qian L, Chen Y, Ouyang D, Zhang W, Han L, Yan J, et al. Field demonstration of enhanced removal of chlorinated solvents in groundwater using biochar-supported nanoscale zero-valent iron. Sci Total Environ. 2020;698:134215. DOI: 10.1016/j.scitotenv.2019.134215.

[18] Zhou X, Chen H, Gao S-H, Han S, Tu R, Wei W, et al. Effects of particle size of zero-valent iron (ZVI) on peroxydisulfate-ZVI enhanced sludge dewaterability. Korean J Chem Eng. 2017;34(10):2672-7. DOI: 10.1007/s11814-017-0187-X.

[19] Crane RA, Scott TB. Nanoscale zero-valent iron: Future prospects for an emerging water treatment technology. J Hazard Mater. 2012;211-212:112-25. DOI: 10.1016/j.jhazmat.2011.11.073.

[20] Comba S, Di Molfetta A, Sethi R. A Comparison between field applications of nano-, micro-, and millimetric zero-valent iron for the remediation of contaminated aquifers. Water Air Soil Pollut. 2011;215:595-607. DOI: 10.1007/s11270-010-0502-1.

[21] Henderson $\mathrm{AD}$, Demond $\mathrm{AH}$. Long-term performance of zero-valent iron permeable reactive barriers: A critical review. Environ Eng Sci. 2007;24(4):401-23. DOI: 10.1089/ees.2006.0071.

[22] Han Y, Yan W. Reductive dechlorination of trichloroethene by zero-valent iron nanoparticles: Reactivity enhancement through sulfidation treatment. Environ Sci Technol. 2016;50(23):12992-3001. DOI: 10.1021/acs.est.6b03997.

[23] Mukherjee R, Kumar R, Sinha A, Lama Y, Saha AK. A review on synthesis, characterization, and applications of nano zero valent iron (nZVI) for environmental remediation. Crit Rev Environ Sci Technol. 2016;46(5):443-66. DOI: 10.1080/10643389.2015.1103832.

[24] Noubactep C, Caré S, Crane R. Nanoscale metallic iron for environmental remediation: prospects and limitations. Water Air Soil Pollut. 2012;223(3):1363-82. DOI: 10.1007/s11270-011-0951-1.

[25] Przepiora A, Roberts J. Zero-valent iron for groundwater remediation - Lessons learned over 20 years of technology use. 2016:28. Available from: https://www.esaa.org/wp-content/uploads/2016/10/16Przepiora2.pdf.

[26] Gu C, Jia H, Li H, Teppen BJ, Boyd SA. Synthesis of highly reactive subnano-sized zero-valent iron using smectite clay templates. Environ Sci Technol. 2010;44(11):4258-63. DOI: 10.1021/es903801r.

[27] Duan R, Dong Y, Zhang Q. Characteristics of aggregate size distribution of nanoscale zero-valent iron in aqueous suspensions and its effect on transport process in porous media. Water. 2018;10:670. DOI: $10.3390 /$ w10060670. 
[28] Dolinová I, Czinnerová M, Dvořák L, Stejskal V, Ševců A, Černík M. Dynamics of organohalide-respiring bacteria and their genes following in-situ chemical oxidation of chlorinated ethenes and biostimulation. Chemosphere. 2016;157:276-85. DOI: 10.1016/j.chemosphere.2016.05.030.

[29] Shi Z, Nurmi JT, Tratnyek PG. Effects of nano zero-valent iron on oxidation-reduction potential. Environ Sci Technol. 2011;45(4):1586-92. DOI: 10.1021/es103185t.

[30] Černík M, Nosek J, Filip J, Hrabal J, Elliott DW, Zbořil R. Electric-field enhanced reactivity and migration of iron nanoparticles with implications for groundwater treatment technologies: Proof of concept. Water Res. 2019;154:361-9. DOI: 10.1016/j.watres.2019.01.058.

[31] Wang SY, Kuo YC, Huang YZ, Huang CW, Kao CM. Bioremediation of 1,2-dichloroethane contaminated groundwater: Microcosm and microbial diversity studies. Environ Pollut. 2015;203:97-106. DOI: 10.1016/j.envpol.2015.03.042.

[32] Villemur R, Lanthier M, Beaudet R, Lépine F. The Desulfitobacterium genus. FEMS Microbiol Rev. 2006;30(5):706-33. DOI: 10.1111/j.1574-6976.2006.00029.x.

[33] Lee T, Tokunaga T, Suyama A, Furukawa K. Efficient dechlorination of tetrachloroethylene in soil slurry by combined use of an anaerobic desdfitobacterium sp. strain Y-5 1 and zero-valent iron. J Biosci Bioeng. 2001;92(5):453-8. DOI: 10.1016/S1389-1723(01)80295-4.

[34] Chaithawiwat K, Vangnai A, McEvoy JM, Pruess B, Krajangpan S, Khan E. Impact of nanoscale zero valent iron on bacteria is growth phase dependent. Chemosphere. 2016;144:352-9. DOI: 10.1016/j.chemosphere.2015.09.025.

[35] Zabetakis KM, Niño de Guzmán GT, Torrents A, Yarwood S. Toxicity of zero-valent iron nanoparticles to a trichloroethylene-degrading groundwater microbial community. J Environ Sci Health A Tox Hazard Subst Environ Eng. 2015;50(8):794-805. DOI: 10.1080/10934529.2015.1019796.

[36] Vogel T, Criddle C, McCarty P. Transformation of halogenated aliphatic compounds. Environ Sci Technol. 1987;21:722-36. DOI: 10.1021/es00162a001.

[37] Maymó-Gatell X, Nijenhuis I, Zinder SH. Reductive dechlorination of cis-1,2-dichloroethene and vinyl chloride by 'Dehalococcoides ethenogenes'. Environ Sci Technol. 2001;35(3):516-21. DOI: 10.1021/es001285i.

[38] Zhang W. Nanoscale iron particles for environmental remediation: An overview. J Nanopart Res. 2003;5(3):323-32. DOI: 10.1023/A:1025520116015.

[39] Bianco C, Patiño Higuita JE, Tosco T, Tiraferri A, Sethi R. Controlled deposition of particles in porous media for effective aquifer nanoremediation. Sci Rep. 2017;7. DOI: 10.1038/s41598-017-13423-y.

[40] Chang Q. Chapter 3 - Sedimentation. In: Chang Q, editor. Colloid and Interface Chemistry for Water Quality Control. Academic Press. 2016:23-35. DOI: 10.1016/B978-0-12-809315-3.00003-7. 